\title{
Model Doubly Fed Induction Generator (DFIG) untuk Analisis Performa Kontrol pada Pembangkit Listrik Tenaga Angin
}

\author{
Agus Yogianto'; Tri Wahyu Oktaviana P. ${ }^{2}$; Ibnu Hajar ${ }^{3}$ \\ 1,2,3 Teknik Elektro, Institut Teknologi PLN \\ ${ }^{1}$ agus.yogianto@itpln.ac.id
}

\begin{abstract}
Studies on the operation of electricity generation from renewable energy with wind power, especially related to the role of the control system in wind power plants are still relatively limited. The role of the control system itself is very important in the conversion of power plants like this. Therefore to find out and investigate the effect of the power converter control system on wind power plants, especially with Double-Fed Induction Generator (DFIG), modeling of wind power plants with DFIG and control systems that can be used for simulations on grids or electric power systems is needed. Research is thus to produce a model of wind power generation with DFIG generators and their control systems that can regulate the conversion of power optimally in operations connected to the electricity grid. Several stages were carried out in this study which consisted of a literature review, preparation of tools for simulations using MATLAB / Simulink, DFIG modeling with a derive in applicable equations, simplification of the model, control design, simulation and analysis. At this stage of the study the results obtained were part of the research stages, namely getting simplified DFIG modeling. This simplified DFIG model is obtained after the formulation of mathematical equations from the DFIG equivalent circuit, deriving equations for the DFIG transient model and constructing the DFIG model in the form of state space. Further simplification of the form of state space obtained by the relationship between the stator and rotor of DFIG.
\end{abstract}

Keywords: DFIG, Wind Turbine, Modelling, Renewable Energy

\section{ABSTRAK}

Studi mengenai pengoperasian pembangkit listrik dari energi terbarukan dengan tenaga angin khususnya terkait dengan peran sistem kontrol pada pembangkit listrik tenaga angin relatif masih sangat terbatas. Peran sistem kontrol sendiri sangat penting di dalam konversi daya pembangkit listrik seperti ini. Oleh sebab itu untuk mengetahui serta menyelidiki pengaruh sistem kontrol konverter daya pada pembangkit listrik tenaga angin khususnya dengan Double-Fed Induction Generator (DFIG) dibutuhkan pemodelan dari pembangkit listrik tenaga angin dengan DFIG serta sistem kontrol yang dapat digunakan untuk simulasi pada jaringan atau sistem tenaga listrik. Penelitian dengan demikian bertujuan untuk menghasilkan model pembangkit listrik tenaga angin dengan generator DFIG beserta sistem kontrolnya yang dapat mengatur konversi daya secara optimal pada operasi yang terkoneksi ke jaringan listrik. Beberapa tahapan dilakukan pada penelitian ini yang terdiri dari kajian literatur, persiapan perangkat untuk simulasi memakai MATLAB/Simulink, pemodelan DFIG dengan penurunan persamaan yang berlaku, penyederhanaan model, disain kontrol, simulasi dan analisis. Pada tahapan penelitian ini hasil yang didapat merupakah sebagian tahapan penelitian yaitu mendapatkan pemodelan DFIG yang disederhanakan. Model DFIG yang disederhanakan ini diperoleh setelah melalui perumusan persamaan matematis dari rangkaian ekuivalen DFIG, menurunkan persamaan untuk model transien DFIG dan menyusun model DFIG dalam bentuk state space. Selanjutnya penyederhanaan dari bentuk state space diperoleh hubungan antara stator dan rotor DFIG.

Kata kunci: DFIG, Turbin Angin, Pemodelan, Energi Terbarukan 


\section{Energi dan Kelistrikan: Jurnal Ilmiah}

Vol. 12, No. 2, Juli - Desember 2020, P-ISSN 1979-0783, E-ISSN 2655-5042

https://doi.org/10.33322/energi.v12i2.1095

\section{PENDAHULUAN}

Konsumsi listrik Indonesia setiap tahunnya terus meningkat sejalan dengan peningkatan pertumbuhan ekonomi nasional [1]. Di Indonesia sendiri, berdasarkan RUPTL PLN tahun 2018, proyeksi pertumbuhan kebutuhan listrik mencapai $6,86 \%$ setiap tahunnya). Oleh karena itu diperlukan jaminan pasokan listrik untuk menunjang berlangsungnya aktivitas dan roda perekonomian di tanah air. Penambahan kapasitas pembangkit listrik dari energi terbarukan mulai berkembang lagi akhir-akhir ini yang juga masuk di dalam program 35.000 MW. Pada program tersebut penambahan kapasitas dari pembangkit listrik energi terbarukan cukup signifikan. Pembangkit listrik tenaga angin adalah salah satu pembangkit listrik energi terbarukan yang mulai dikembangkan saat ini dengan kapasitas relatif besar di Sulawesi Selatan. Turbin angin digerakkan oleh kecepatan angin (energi primer) untuk menghasilkan daya listrik (energi sekunder) [2].

Walaupun terbatas sebaran dari pembangkit tersebut di wilayah Indonesia, tetapi apabila pembangkit tersebut terhubung ke jaringan atau sistem tenaga listrik, maka peran dan dampak pembangkit tersebut akan dirasakan oleh jaringan atau sistem tenaga listrik. Sementara itu studi mengenai pengoperasian pembangkit listrik tenaga angin khususnya terkait dengan peran sistem kontrol pada pembangkit listrik tenaga angin masih terbatas.

Oleh sebab itu untuk mengetahui pengaruh dan peran sistem kontrol konverter daya pada pembangkit listrik tenaga angin khusus dengan Double-Fed Induction Generator (DFIG) dibutuhkan pemodelan dari pembangkit listrik tenaga angin serta sistem kontrol yang dapat digunakan untuk simulasi di jaringan atau sistem tenaga, sehingga dapat digunakan untuk analisis performa pembangkit listrik serta peran kontrol konverter daya pada operasi sistem. Penelitian ini membahas pemodelan dari DFIG sebagai salah satu tahapan awal untuk menilai performa sistem kontrol Pembangkit Listrik Tenaga Angin melalui simulasi di MATLAB Simulink.

DFIG merupakan generator induksi dimana terminal stator terhubung langsung ke jaringan, sedangkan rotor belitan terhubung melalui slip ring ke konverter sumber tegangan tiga fase [3]. Dewasa ini DFIG sudah umum digunakan di industri turbin angin untuk turbin angin besar [4]. Dibandingkan menggunakan turbin angin generator induksi kecepatan tetap, turbin angin berbasis DFIG menawarkan beberapa keuntungan termasuk operasi kecepatan variabel, dan kemampuan empat-kuadran operasi daya aktif dan reaktif [5]. Sekitar dua pertiga turbin angin dioperasikan dengan DFIG, sementara sekitar sepertiga dari populasi turbin angin dioperasikan dengan generator sinkron [6].

\section{METODE PENELITAN}

\subsection{Metode Perencanaan}

Pekerjaan penelitian dilakukan dengan terlebih dahulu merencanakan garis besar penelitian dan metodologi pada penelitian. Alur penelitian dapat dilihat pada Gambar 1 berikut:

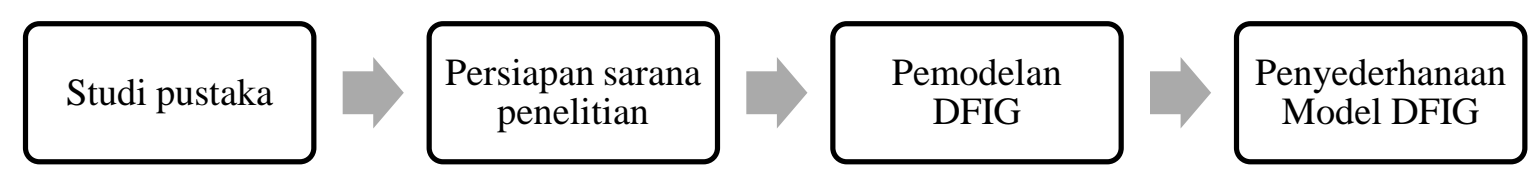

Gambar 1. Alur Penelitian 


\subsection{Metode Pelaksanaan Penelitian}

Secara garis besar metodologi penelitian, dengan tahapan studi literatur, persiapan sarana termasuk perangkat lunak, pemodelan DFIG, pemodelan sistem kontrol, simulasi, analisis dan diskusi untuk selanjutnya menyusun konsep laporan akhir. Tahapan penelitian pada artikel ini terbatas pada pemodelan DFIG. Berikut adalah langkah-langkah untuk memperoleh model mesin DFIG:

1. Persiapan sarana

Pada tahap ini persiapan sarana dilakukan dengan:

- Memeriksa software MATLAB/SIMULINK, terkait kelengkapan dari library, fungsi dan lain-lain untuk persyaratan awal apakah bisa digunakan untuk pemodelan dan simulasi.

- Mencoba membuat model sederhana dari mesin induksi.

2. Pemodelan

Pada tahapan ini mulai dibangun model turbin angin dan generator. Model generator yang dibangun merupakan model DFIG dengan cara:

- Menyusun rangkaian ekivalen DFIG

- Merumuskan persamaan matematis dari rangkaian ekivalen DFIG

- Menurunkan persamaan untuk memperoleh model transien DFIG

- Menyusun model DFIG dalam bentuk state space

- Menyederhanakan persamaan model DFIG

\section{HASIL DAN PEMBAHASAN}

\subsection{Doubly Fed Induction Generator (DFIG)}

DFIG merupakan singkatan dari doubly fed induction generator. Konfigurasi turbin angin jenis ini adalah terminal stator terhubung secara langsung ke grid sedangkan rotor terhubung melalui slip ring ke converter 3 fasa. Nama doubly fed itu sendiri diperoleh karena keduanya, baik rotor maupun stator terhubung ke grid. Gambar 2 berikut adalah konfigurasi Varible Speed Wind Turbine (VSWT) dengan menggunakan DFIG.

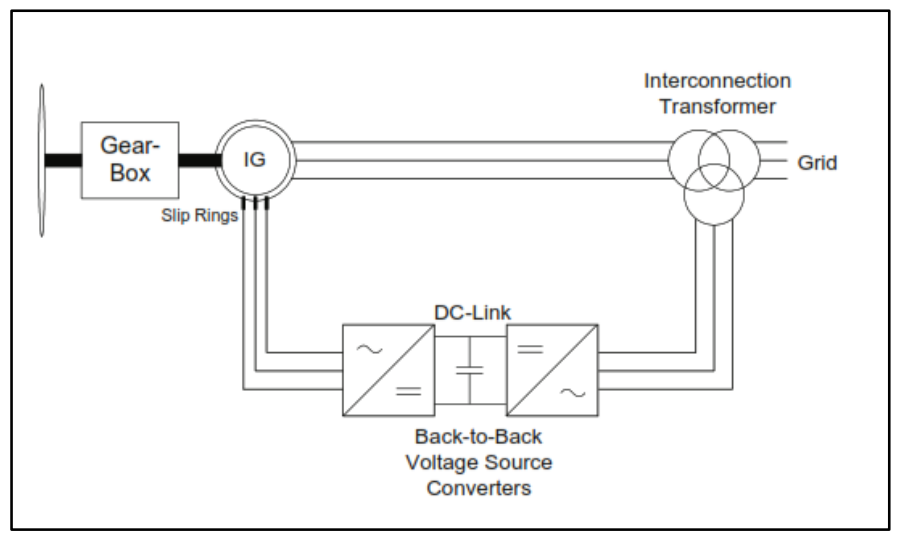

Gambar 2. Konfigurasi VSWT Menggunakan DFIG [3]

\subsection{Batasan Pemodelan DFIG}

Penentuan batas-batas dalam pemodelan diperlukan agar tahapan dalam pemodelan dapat dilakukan pada keadaan yang sama. Berikut adalah batasan pada pemodelan ini: 


\section{Energi dan Kelistrikan: Jurnal Ilmiah}

Vol. 12, No. 2, Juli - Desember 2020, P-ISSN 1979-0783, E-ISSN $2655-5042$

https://doi.org/10.33322/energi.v12i2.1095
a. Mesin simetris
b. Saturasi magnetic, rugi-rugi fisis dan belitan diabaikan
c. Dinamika transfer massa diabaikan [3]
d. Switching sistem diabaikan
e. Turbin angin beroperasi pada sudut bilah yang tetap
f. Model kontrol terbatas pada kontrol daya aktif dan daya reaktif

\subsection{Pemodelan DFIG}

Model transien yang dikembangkan di sini digunakan untuk menjelaskan perilaku mesin DFIG itu sendiri [3]. Pemodelan pada penelitian ini menggunakan prinsip orientasi medan koordinat d-q. Dimana d merupakan orthogonal direct dan q merupakan komponen quadrature. Pada sistem koordinat d-q hubungan rotor, arus magnetisasi hanya berada pada sumbu-d dan tegangan stator berada pada sumbu-q [6]. Gambar 3 merupakan rangkaian ekivalen DFIG lengkap dengan konstanta yang terdapat pada stator dan rotor.

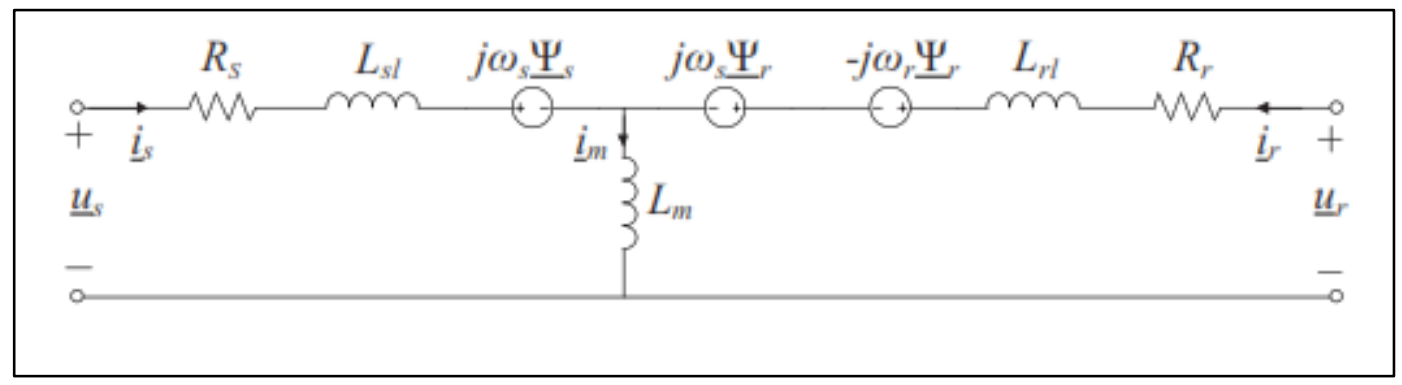

Gambar 3. Rangkaian Ekivalen DFIG [3]

Variabel dan konstanta pada gambar 3 adalah :

$\underline{u_{s}}$ : tegangan stator/ tegangan grid ( vektor kompleks)

$\underline{u_{r}}$ : tegangan rotor (dalam vektor kompleks)

$\underline{\Psi_{s}}$ : fluks stator (dalam vektor kompleks)

$\underline{\Psi_{r}}:$ fluks rotor (dalam vektor kompleks)

$\underline{i_{s}}:$ arus stator (dalam vector kompleks)

$i_{r}$ : arus rotor (dalam vector kompleks)

$\bar{R}_{S}$ : tahanan stator

$R_{r}:$ tahanan rotor

$L_{s}:$ induktansi stator

$L_{r}$ : induktansi rotor

$L_{m}:$ induktansi magnet

$\omega_{s}$ : frekuensi jala-jala

$\omega_{r}$ : frekuensi rotor

Persamaan yang merepresentasikan dinamika DFIG adalah:

$$
\begin{aligned}
& \underline{u_{s}}=R_{s} \underline{i_{s}}+\frac{d \underline{\Psi_{s}}}{d t}+j \omega_{s} \underline{\Psi_{s}} \\
& \underline{u_{r}}=R_{r} \underline{i_{r}}+\frac{d \Psi_{r}}{d t}+j\left(\omega_{s}-\omega_{r}\right) \underline{\Psi_{r}}
\end{aligned}
$$


$\underline{\Psi_{s}}=L_{s} \underline{i_{s}}+L_{m} \underline{i_{r}}$

$\underline{\Psi_{r}}=L_{m} \underline{i_{s}}+L_{r} \underline{i_{r}}$

Kemudian dengan mensubstitusikan persamaan (3) dan (4) ke persamaan (1) dan (2), maka diperoleh persamaan:

$\underline{u_{s}}=\left(\frac{R_{s}}{L^{\prime}}+j \omega_{s}\right) \underline{\Psi_{s}}+\frac{d \underline{\Psi_{s}}}{d t}-k_{r} \frac{R_{s}}{L_{s}^{\prime}} \underline{\Psi_{r}}$

$\underline{u_{r}}=-k_{s} \frac{R_{r}}{L_{r}^{\prime}} \underline{\Psi_{s}}+\frac{d \underline{\Psi_{r}}}{d t}-\left(\frac{R_{r}}{L_{r}^{\prime}}+j\left(\omega_{s}-\omega_{r}\right)\right) \underline{\Psi_{r}}$

dengan :

$k_{s}=\frac{L_{m}}{L_{s}} ; k_{r}=\frac{L_{m}}{L_{r}} ; L_{s}^{\prime}=\sigma L_{s} ; L_{r}^{\prime}=\sigma L_{r} ; \sigma=1-k_{s} k_{r}$

Hubungan antara fluks dan kecepatan rotor adalah:

$\frac{J}{p} \frac{d \omega_{r}}{d t}=\frac{3}{2} p \frac{k_{r}}{L_{s}^{\prime}}\left(\Psi_{r d} \Psi_{s q}-\Psi_{r q} \Psi_{s d}\right)-T_{L}-b \frac{\omega_{r}}{p}$

Jika dibentuk dalam state space, maka model mesin DFIG diuraikan pada persamaan (8) di bawah ini.

$$
\begin{gathered}
{\left[\begin{array}{c}
\frac{d \Psi_{s d}}{d t} \\
\frac{d \Psi_{s q}}{d t} \\
\frac{d \Psi_{r d}}{d t} \\
\frac{d \Psi_{r q}}{d t} \\
\frac{d \omega_{r}}{d t}
\end{array}\right]=\left[\begin{array}{ccccc}
-\frac{R_{s}}{L^{\prime}} & \omega_{s} & k_{r} \frac{R_{s}}{L_{s}^{\prime}} & 0 & 0 \\
-\omega_{s} & -\frac{R_{s}}{L^{\prime}{ }_{s}} & 0 & k_{r} \frac{R_{s}}{L_{s}^{\prime}} & 0 \\
k_{s} \frac{R_{r}}{L_{r}^{\prime}} & 0 & -\frac{R_{r}}{L_{r}^{\prime}} & \omega_{s}-\omega_{r} & 0 \\
0 & k_{s} \frac{R_{r}}{L_{r}^{\prime}} & \omega_{r}-\omega_{s} & -\frac{R_{r}}{L_{r}^{\prime}} & 0 \\
0 & \frac{3}{2} \frac{p^{2}}{J} \frac{k_{r}}{L^{\prime} \Psi_{r d}} & 0 & -\frac{3}{2} \frac{p^{2}}{J} \frac{k_{r}}{L_{s}^{\prime}} \Psi_{s d} & -\frac{b}{J}
\end{array}\right]\left[\begin{array}{c}
\Psi_{s d} \\
\Psi_{s q} \\
\Psi_{r d} \\
\Psi_{r q} \\
\omega_{r}
\end{array}\right]} \\
+\left[\begin{array}{ccccc}
1 & 0 & 0 & 0 & 0 \\
0 & 1 & 0 & 0 & 0 \\
0 & 0 & 1 & 0 & 0 \\
0 & 0 & 0 & 1 & 0 \\
0 & 0 & 0 & 0 & -\frac{p}{J}
\end{array}\right]\left[\begin{array}{l}
\mathrm{u}_{s d} \\
\mathrm{u}_{s q} \\
\mathrm{u}_{r d} \\
\mathrm{u}_{r q} \\
T_{L}
\end{array}\right]
\end{gathered}
$$

\subsection{Penyederhanaan Model DFIG}

Penyederhanaan model bertujuan agar simulasi DFIG pada MATLAB dapat dibentuk dalam bentuk matematis sederhana, sehingga memudahkan dalam membuat model simulasinya. Berdasarkan Snyder (2012) beberapa hal dari persamaan (8) dapat diabaikan atau dianggap bernilai konstan [3]. Sehingga, diperoleh bentuk yang lebih sederhana. Asumsi pada penyederhanaan model ini adalah: 


\section{Energi dan Kelistrikan: Jurnal Ilmiah}

Vol. 12, No. 2, Juli - Desember 2020, P-ISSN 1979-0783, E-ISSN $2655-5042$

https://doi.org/10.33322/energi.v12i2.1095
a. $\frac{d \Psi_{s}}{d t}=\frac{d \Psi_{r}}{d t}=0$
b. Kecepatan rotor konstan
c. Torsi mekanis konstan
d. Kontrol arus diabaikan, karena kerja dari kontrol arus tersebut hanya sesaat

Dengan adanya asumsi tersebut, maka persamaan (2) dapat disederhanakan dan mensubstitusikan persamaan (4) ke persamaan tersebut menjadi:

$$
\begin{aligned}
& \underline{u_{r}}=R_{r} \underline{i_{r}}+j\left(\omega_{s}-\omega_{r}\right)\left(L_{m} \underline{i_{s}}+L_{r} \underline{i_{r}}\right) \\
& \underline{u_{r}}=R_{r} \underline{i_{r}}+s X_{m} \underline{i_{s}}+j s X_{r} \underline{i_{r}}
\end{aligned}
$$

Dengan

$$
X_{m}=\omega_{s} L_{m} ; X_{r}=\omega_{s} L_{r} ; X_{s}=\omega_{s} L_{s} ; s=\operatorname{slip}=\frac{\omega_{s}-\omega_{r}}{\omega_{s}}
$$

Begitu juga persamaan (1) dapat disederhanakan menjadi:

$$
\underline{u_{s}}=\underline{i_{s}}\left(R_{s}+j \omega_{s} L_{s}\right)+j \omega_{s} L_{m} \underline{i_{r}}
$$

Dari persamaan (11) dapat diperoleh arus stator yaitu:

$$
\underline{i_{s}}=\frac{u_{s}-j X_{m} \underline{i_{r}}}{R_{S}+j X_{S}}
$$

\section{KESIMPULAN DAN SARAN}

\subsection{KESIMPULAN}

Berdasarkan penelitian yang dilakukan maka dapat diperoleh kesimpulan bahwa dari studi performa kontrol konverter daya pada pembangkit listrik, pada tahapan ini telah diturunkan suatu model DFIG yang didapat dari beberapa tahapan agar dapat dibuat rancangan kontrol konverter daya aktif dan daya reaktif. Hasil akhir model DFIG yang diperoleh adalah berupa bentuk hubungan sederhana yang menghubungkan stator yang berelasi ke sistem dengan rotor yang berelasi ke penggerak.

\subsection{SARAN}

Saran untuk penelitian ini adalah agar dilanjutkan hingga mencapai tahap simulasi dan analisis operasi pembangkit listrik tenaga angin dengan DFIG

\section{UCAPAN TERIMA KASIH}

Penulis mengucapkan terima kasih kepada Institut Teknologi PLN Jakarta dan LPPM atas kesempatan kepada tim penelitian dan dukungan baik moril maupun materiil serta pendanaan sehingga kegiatan penelitian dapat terlaksana dengan baik. 


\section{DAFTAR PUSTAKA}

[1] M. Muchlis and A. D. Permana, "Proyeksi Kebutuhan Listrik PLN 2003 s.d. 2020," Pengemb. Sist. Kelistrikan dan Menunjang Pembang. Nas. Jangka Panjang, p. 11 Halaman, 2003, [Online]. Available: http://www.oocities.org/markal_bppt/publish/slistrk/slmuch.pdf.

[2] H. Pulgar, "Basics of DFIG power generation Basics of DFIG power generation," Valparaiso, Chile, 2015. doi: 10.13140/2.1.2970.2089.

[3] M. A. SNYDER, "Development of Simplified Models of Doubly-Fed Induction Generators," Chalmers University of Technology, 2012.

[4] G. Li and L. Hang, "Control of Doubly-fed Induction Generators for Wind Turbines," Model. Mod. Control Wind Power, pp. 37-62, 2017, doi: 10.1002/9781119236382.ch3.

[5] T. M. Masaud, S. Member, and P. K. Sen, "Modeling and Control of Doubly Fed," 2011, doi: 10.1109/NAPS.2011.6025122.

[6] H. M. S. Firdaus, M. Y. Halyani, E. Z. Ahmad, I. Norain, Z. M. Zulfattah, and M. S. Azizi, "Modeling and simulation of doubly fed induction generator for wind turbine," ARPN J. Eng. Appl. Sci., vol. 11, no. 11, pp. 7331-7335, 2016. 